\title{
UM MINISTÉRIO COM CULTURA \\ GILBERTO GIL E OS EXERCÍCIOS DE ANTROPOLOGIA APLICADA
}

\author{
Adriana Donato dos Reis ${ }^{1}$ \\ Jean Segata $^{2}$
}

No dia 02 janeiro de 2003, na solenidade de transmissão de cargos que dava início ao primeiro governo do presidente Lula, o então Ministro da Cultura Gilberto Gil defendeu em seu discurso de posse uma ampliação profunda do conceito de cultura. Ela incluía culturas populares, afro-brasileiras, indígenas, mulheres, LGBT, periferias, novas tecnologias, entre muitas outras, e não apenas ao universo restrito das belas-artes de origem europeia. Nas suas palavras:

\begin{abstract}
O que entendo por cultura vai muito além do âmbito restrito e restritivo das concepções acadêmicas ou dos ritos e da liturgia de uma suposta "classe artística e intelectual". Cultura, como alguém já disse, não é apenas "uma espécie de ignorância que distingue os estudiosos". [...] Cultura como tudo aquilo que, no uso de qualquer coisa, se manifesta para além do mero valor de uso. Cultura como aquilo que, em cada objeto que produzimos, transcende o meramente técnico. Cultura como usina de símbolos de um povo. Cultura como conjunto de signos de cada comunidade e de toda a nação.[...] Desta perspectiva, as ações do Ministério da Cultura deverão ser entendidas como exercicios de antropologia aplicada" (Gil, apud Almeida et al., 2013: 251, grifo nosso) ${ }^{3}$.
\end{abstract}

Ainda em seu discurso, Gilberto Gil também enfatizou a importância do papel ativo do Estado na democratização cultural e de modo perspicaz afirmou que “[...] formular políticas culturais é fazer cultura [...]. Não cabe ao Estado fazer cultura, mas, sim, criar condições de acesso universal aos bens simbólicos. Não cabe ao Estado fazer

\footnotetext{
${ }^{1}$ Pontifícia Universidade Católica do Rio Grande do Sul, Brasil. E-mail: adriarte@gmail.com ORCID id: https://orcid.org/0000-0003-3543-2172

${ }^{2}$ Universidade Federal do Rio Grande do Sul, Brasil. E-mail: jeansegata@ufrgs.br ORCID id: https://orcid.org/0000-0002-2544-0745

${ }^{3}$ Gilberto Passos Gil Moreira, nasceu no dia 26 de junho de 1942 na cidade de Salvador, pai de oito filhos, casado com Flora Gil Moreira, cantor, compositor, instrumentista, produtor musical, com quase 60 discos lançados. Formou-se em administração de empresas pela Universidade Federal da Bahia. Em 1987 foi presidente da Fundação Gregório de Matos em Salvador - Bahia, órgão que correspondia à Secretaria Municipal de Cultura. Entre 1989 e 1992, foi vereador na Câmara Municipal de Salvador, pelo Partido Verde. Vencedor de nove prêmios Grammys. Em 1999, foi nomeado “Artista da Paz", pela UNESCO. Foi também embaixador da ONU.
} 
cultura, mas, sim, promover o desenvolvimento cultural geral da sociedade" (Gil, apud Almeida et al., 2013: 258). A ampliação do conceito de cultura da gestão Gil à frente do Ministério da Cultura (2003-2008) encontrava o que para ele era o momento propício e oportuno para a sociedade refletir sobre o papel da cultura no processo de tomada de consciência e autoestima revolucionária. O que ele buscava era uma profunda mudança que promovesse" a percepção do conceito de cultura e como vamos transformá-lo num instrumento privilegiado para a transformação social" (id.). A diversidade cultural, na visão do ministro, é um conceito que nos ajuda a dinamizar uma imagem ultrapassada que foi inspiradora durante o período de um Estado autoritário. A convenção da UNESCO, com relação à diversidade cultural, autorizava os países, ajudava a promover a diversidade cultural como valor de desenvolvimento e como ativo, inclusive um desenvolvimento para além do PIB (Gil, apud Almeida et al., 2013: 413 - 414)

Em seus primeiros discursos, o Ministro Gilberto Gil também falava que não se poderia pensar em fazer cultura sem pensar em economia, pois como fazer e criar ações sem orçamento? Não por acaso, apareciam em alguns espaços na mídia frases como: "Gil pede dinheiro"; "1\% do orçamento para a cultura"; "Gil chora por recursos". Mas os recursos, segundo ele, eram um primeiro passo para pensar a cultura como ativo e desenvolvimento sustentável, pois o “desenvolvimento, para ser sustentável, deve se alimentar e estar articulado em torno de diferentes dimensões da vida social, cultural, ambiental, econômica e espacial” (id, p. 263). Assim, segundo Gil, o Ministério não poderia deixar de fazer o que é sua função de órgão gestor, que era o de formular e executar Políticas Públicas para a cultura oferecendo condições adequadas para o trabalho artístico-cultural de forma digna e democrática. Seu foco era aproximar o Ministério da Cultura da vida cotidiana das pessoas "transformando-a na casa de todos os que pensam e fazem o Brasil” (id: 262). Não por menos,

\footnotetext{
entre as análises contemporâneas acerca da gestão cultural no Brasil, há uma unanimidade em torno dos avanços obtidos no período do governo Lula pelo Ministério da Cultura. Tais avaliações têm, inclusive, repercussão internacional. Os primeiros anos da gestão Gil, em especial, foram marcados por mudanças radicais no comportamento do Estado, do governo federal frente à gestão da cultura (Calabre, 2015: 34).
}

Mas, no que implicaria a ampliação do conceito de cultura na formulação das políticas públicas e qual a importância dessa nova ideia? Como um conjunto de experiências, práticas, tradições e saberes populares e étnicos que fazem parte do escopo de defesas históricas da antropologia passaram a caracterizar, na esfera pública, uma ideia 
ampliada e democratizante de cultura? Neste trabalho, descreveremos algumas diretrizes e políticas gestadas na administração de Gilberto Gil à frente do MinC, na esfera do que ele chamou de "exercícios de antropologia aplicada", fundamentais para as mudanças que passaram a integrar a sua agenda de governo - um marco na política cultural brasileira.

\section{Gilberto Gil, Ministro da Cultura (2003-2008)}

Em 2003, o presidente Luiz Inácio Lula da Silva nomeou Gilberto Gil Ministro da Cultura. O principal objetivo desta gestão era incorporar o conceito de ampliação de cultura e desta forma promover a diversidade cultural, manter os valores culturais simbólicos e ampliar o olhar para outros modos de produção, sobretudo a valorização da cultura popular. Gil ficou na função de Ministro da Cultura até 30 de julho de 2008.

Gilberto Gil fez críticas à ausência de uma política cultural ativa, que caracterizou a gestão anterior, consubstanciada nas leis de incentivo que compreendiam a "cultura como um bom negócio" e favoreciam mais as corporações do campo artístico do que os artistas e a população (Rubim, 2016). Gil assumiu o compromisso de que o público do Ministério da Cultura seria toda a sociedade brasileira e não apenas os grandes artistas, as empresas e os profissionais ligados ao patrimônio. O diálogo com a sociedade permitiria enfrentar os autoritarismos e formular e realizar políticas culturais em circunstâncias democráticas foi a promessa de uma nova agenda do Ministério da Cultura. Este período representou uma mudança na política cultural no Brasil, com um novo modelo de gestão compartilhada, não somente um Estado mais democrático, mas principalmente através da participação da sociedade civil, nas construções das novas diretrizes e novas políticas culturais formuladas entre 2003 e 2008, como por exemplo, a criação de Câmaras Setoriais da Cultura, conferências regionais, implementação do Sistema Nacional de Cultura (SNC), a construção das diretrizes para o Plano Nacional de Cultura (PNC) e dos Pontos de Cultura, são objeto de estudo no campo das políticas culturais.

Em 2003, o Presidente da República, Luiz Inácio Lula da Silva, aprovou a reestruturação do Ministério da Cultura (MinC) por meio do Decreto 4.805/2003, que lhe deu a estrutura vigente até 2018 - hoje, transformado em Secretaria Especial da Cultura do Ministério do Turismo. Sob a gestão de Gilberto Gil, o Ministério foi reformulado e foram criadas novas secretarias: de Políticas Culturais (SPC); Programas e Projetos 
Culturais (SPPC); Audiovisual (SAV); Identidade e Diversidade Cultural (SID); Articulação Institucional (SAI) e Fomento e Incentivo à Cultura (SEFIC), com ênfase na produção de uma postura ativa do Estado no setor. Também foram criadas seis Representações Regionais (nos estados de Minas Gerais, Pará, Pernambuco, Rio de Janeiro, Rio Grande do Sul e São Paulo) e seis Secretarias. Em 2010, foi criada mais outra representação, na Bahia; em 2014, em Florianópolis (SC) e em 2015, no Maranhão. Em 2017, o MinC tinha o total de oito representações. Atualmente, a Secretaria Especial da Cultura, vinculada ao Ministério da Cidadania, mantém apenas seis escritórios regionais.

Ainda a partir de 2003, iniciou-se um conjunto de formulações de políticas - um deles foi o programa Cultura para Todos, com uma série de seminários, que tinha como objetivo discutir com a sociedade um novo modelo de financiamento cultural. Os temas abordados durante o seminário foram: O Ministério da Cultura e o Financiamento da Produção Cultural, O Papel do Governo Federal no Financiamento da Cultura, As Empresas Estatais e o Financiamento da Cultura, As Empresas Privadas e o Financiamento da Cultura, As Leis Estaduais e Municipais de Incentivo à Cultura. O primeiro evento foi no Ministério da Cultura, em Brasília, e posteriormente ocorreram outros encontros no Rio de Janeiro, Recife, Cuiabá, Belo Horizonte, São Paulo, Porto Alegre, Belém e Salvador (EBC, 2003). Estas e outras políticas culturais - como por exemplo as mudanças na Lei Rouanet, a criação dos Pontos de Cultura, a aprovação da Emenda Constitucional (EC) n ${ }^{\circ} 48 / 2005$ - que acrescentou o parágrafo $3^{\circ}$ ao art. 215 da Constituição Federal instituindo o Plano Nacional de Cultura com suas políticas públicas culturais abrangendo transparência e governança - a Emenda Constitucional $n^{\circ} 42$ inseriu o $\S 6^{\circ}$ no art. 216, facultando aos "Estados e ao Distrito Federal vincular a fundo estadual de fomento à cultura até $0,05 \%$ de sua receita tributária líquida para o financiamento de programas e projetos culturais" (Brasil, 1988).

Em 2007, foi lançado o Programa Mais Cultura, que representava o reconhecimento da cultura como necessidade básica. Cabe destacar aqui que no dia 20 de outubro de 2005, a Conferência da Unesco realizada em Paris, aprovou a Convenção Internacional de Proteção e Promoção da Diversidade Cultural. Esta convenção foi assinada por 50 países, entre China, Europa, Canadá e ratificada oficialmente em 35 países. No Brasil o texto da Convenção foi aprovado por meio do Decreto no 485/2006. Tendo sido foi promulgada através do de Decreto $n^{\circ} 6.177 \mathrm{em} 1^{\circ}$ de agosto de 2007 (Brasil, 2007). 
Em 2006 e 2007, também ocorreram o Seminário Nacional dos Direitos Autorais, o I Fórum Nacional de TVs Públicas e o Seminário Internacional de Diversidade Cultural. Este último, teve como propósito ampliar o debate sobre a diversidade cultural e sobre as experiências de políticas públicas da cultura nas Américas. O evento foi proposto pelo Governo brasileiro, tendo sido apresentado à Comissão Interamericana de Cultura da Organização dos Estados Americanos (OEA). O evento contou com a presença de autoridades e personalidades do meio cultural do Equador, Guatemala, Paraguai, Peru, Canadá, Estados Unidos, Suriname, Venezuela, México, Argentina, Jamaica, Haiti e Honduras.

Em 2003, em um pronunciamento em Fortaleza, Gil expôs a visão estratégica do Ministério da Cultura em sua gestão. Primeiramente, era urgente abrir o leque, ampliar a visão e trabalhar no entrelaçamento entre política, economia, educação e cultura. O que se via no Brasil ao longo dos últimos anos passava longe disso. Ele apontou três questões como desafios para o MinC: (i) a retomada do papel institucional do órgão formulador e executor de uma política cultural no país; (ii) a reforma administrativa e a capacidade institucional para operar tais políticas e; (iii) a obtenção de recursos financeiros para a implementação dessas políticas, ações e programas. Essas três ações eram fundamentais para que o MinC pudesse atuar em seu papel estratégico de promotor de desenvolvimento cultural, garantindo a inclusão cultural e pluralidade dos seus fazeres, o acesso universal, a criação e a produção dos bens e serviços culturais (Gil, apud Almeida et al., 2013).

O novo modelo de política que se deu a partir de 2003, com a formulação das principais políticas, como a construção do Plano Nacional de Cultura; as conferências do Sistema Nacional de Cultura; as audiências da reforma da Lei Rouanet e a construção do Programa Cultura Viva: Pontos de Cultura e o Programa Mais Cultura. Além das propostas emanadas pelo Estado na administração do Ministro Gilberto Gil, este estudo apresenta a participação de grupos da sociedade civil e como se equacionaram as relações de poder no processo de constituição da agenda cultural numa genealogia dos debates em torno da Lei de Incentivo à Cultura, do Sistema Nacional de Cultura e do Plano Nacional de Cultura. A Lei Rouanet existe há três décadas, mas foi na gestão de Gil que se discutiu sua substituição pela nova Lei Pró-Cultura, que tramitou no Congresso Nacional desde 2010 até 2014 , tendo sido arquivada.

O Plano Nacional de Cultura, previsto pelo artigo 215 da Constituição Federal de 1988, foi elaborado após a realização de fóruns, seminários e consultas públicas com a 
sociedade civil que aconteceram em todo o Brasil a partir de 2005. Ele foi aprovado em dezembro de 2010, após dois anos de tramitação no Congresso Nacional, tornando-se a Lei 12.343/2010, que deveria embasar as ações da área cultural na esfera pública até o ano de 2020. Tratou-se de um instrumento de planejamento que organizava, regulava e norteava as políticas setoriais na perspectiva do Sistema Nacional de Cultura, sendo composto por diretrizes, estratégias, ações e metas que estabeleciam os deveres do Estado e a participação social.

A Lei Cultura Viva (Lei 13.018/14) foi um marco histórico na Política Nacional de Cultura. Ela foi responsável pelo Programa Cultura Viva e sua ação estruturante mais conhecida é representada pelos Pontos de Cultura. São grupos, coletivos e entidades de natureza ou finalidade cultural que desenvolvem e articulam atividades culturais em suas comunidades e através de redes, reconhecidos e certificados pelo Ministério da Cultura. Gilberto Gil, ao assumir o cargo, dizia que ainda ficava perplexo com a situação paradoxal em que o nosso país se encontrava: como um país tão rico, com diversas expressões culturais e valores simbólicos, tem "um Estado tão ausente, tão desarticulado, tão omisso e tão medíocre em suas intervenções no campo da cultura?". Como era possível, "nossos ‘outros' sociais, os excluídos da cidadania cultural” (Gil, apud Almeida et al.: 270).

Em 2005, em um pronunciamento, Gil afirmava que, de certo modo, o MinC ainda estava na adolescência, tanto na forma de fazer políticas públicas de cultura quanto no modo como os poderes públicos tratavam a cultura. Ele se perguntava como superar esse quadro senão pela democratização da cultura no país. Foi quando o Ministério da Cultura foi reestruturado através de decreto. Essa nova estrutura deu suporte à elaboração de novos projetos, ações e políticas. Nas palavras de Rubim (2009), Gil confrontou o autoritarismo e o elitismo, a adoção do termo ampliação do conceito de cultura, a valorização da cultura no sentido antropológica, permitiu que o Ministério saísse do círculo da cultura erudita, abrindo novas fronteiras. Gil inaugura a atuação do Ministério com programas de apoio a culturas indígenas, além da abertura conceitual, mas também uma abertura na forma de atuação para além de uma visão fechada entre sistemas intelectuais e até mesmo discriminadores de certas culturas, o que marcou o início para uma democratização das políticas culturais. Segundo Bolaño et al. (2010), esse período representou uma mudança no modelo de gestão cultural no Brasil, sobretudo na atuação do Estado mais presente e participativo e nas novas diretrizes para as políticas culturais. Ações como a criação de Câmaras Setoriais da cultura, conferências regionais, 
implementação do Sistema Nacional de Cultura (SNC) e a construção das diretrizes para o Plano Nacional de Cultura (PNC).

Logo no início de sua gestão, ainda em 2003, Gil já falava sobre a complementação da reforma do MinC que estava sendo implementada e sobre a importância de se valorizar o cinema brasileiro, porque desenvolvia a indústria cinematográfica, gerava empregos e valorizava o Brasil. Na época, ele anunciou a construção de centros culturais em todo o país - as Casas de Cultura nas periferias, que eram elementos de um projeto ousado e caro para ele e, como era de conhecimento público, era a razão pela qual Gil pretendia conseguir aumentar o orçamento da cultura. O projeto era sair de 0,14\% em 2002 para 1\% do orçamento da União ainda em 2004. Contudo, naquele ano, não se atingiu essa meta, ainda que o aumento substancial, de $70 \%$ maior que em 2003 foi considerado um recorde histórico.

Uma reportagem divulgada no portal de internet UOL, intitulada Orçamento em Cultura aumenta $142 \%$ desde 2003, apontou que

[...] o orçamento global do Ministério da Cultura, entre 2003 e 2008, aumentou $142 \%$. Um levantamento da ONG Contas Abertas mostra que a pasta passou de R\$ 359,8 milhões no início do governo Lula para R\$ 868,6 milhões em 2008 (UOL, 2009).

As definições da política cultural na gestão Gilberto Gil tinham como fio condutor a preservação do patrimônio histórico brasileiro. Elas destacavam a diversidade cultural, as culturas populares, a cultura de massa e toda a forma de expressão cultural, considerando os fazeres e sentidos de todas as regiões do Brasil. Conforme se referiu em seu discurso de posse, Gil defendia uma política que representasse a cultura brasileira e, além disso, trouxesse a ideia da "ampliação do conceito de cultura", afirmando que as ações do Ministério da Cultura deveriam ser entendidas "como exercícios de antropologia aplicada", ou seja, a cultura no sentido antropológico. Era hora de deixar de apenas replicar os modelos europeus da "alta cultura", das "belas artes", da "civilização", para pensar em um ministério que refletisse a gente, a história e a diversidade do Brasil. Igualmente, era hora de superar os processos de formulação da política nacional para além da preservação do patrimônio cristão e militar. Para Gilberto Gil, era chegada a hora de um Ministério que refletisse a dimensão simbólica da cultura brasileira, era a hora de pensar a cultura como transformação: 
Dimensão antropológica, como dimensão simbólica da existência social brasileira, como o conjunto dinâmico de todos os atos criativos de nosso povo, aquilo que, em cada objeto que um brasileiro produz, transcende o aspecto meramente técnico. Cultura como "usina de símbolos" de cada comunidade e de toda a nação, eixo construtor de identidades, espaço de realização da cidadania. Estas são formulações retiradas de discursos do Ministro Gilberto Gil e que se vêm refletidas em diversos programas e ações do ministério e de suas instituições (Botelho, 2007: 128).

A economia da cultura, assunto relativamente novo no Brasil, também foi uma abordagem em sua gestão. Uma das premissas era a de que um bem simbólico "é um produto cultural, político e econômico - simultaneamente" (Gil, apud Almeida et al., 2013, p. 242). O MinC estabeleceu um novo formato de diálogo com a sociedade a partir da construção de produtivas interlocuções entre o poder público e os agentes culturais, isto é, artistas e outros grupos. Gil foi, assim, essencial para a abertura da construção de uma nova política cultural no Brasil:

As gestões de Gilberto Gil (2003-2008) e Juca Ferreira (2008-2010) no governo Lula, com (muitos) acertos e (alguns) erros, colocaram as políticas culturais em um expressivo patamar, nacional e internacional, nunca antes alcançado pelo Ministério da Cultura no país. Elas enfrentaram as tristes tradições - ausências, autoritarismos e instabilidades - que marcaram a trajetória das políticas culturais nacionais e inauguraram vigorosas políticas culturais em diversas áreas (Rubim 2016: 9).

Comandado por Gil durante o governo Lula o MinC passou por momentos de “superações". Nos discursos pronunciados no primeiro ano de gestão, Gil privilegiou dois temas que tinha como meta: superar a tradição da ausência e enfatizar o papel ativo do Estado na formulação e implementação de políticas de cultura. Rubim (2008) lembra que a marca de sua gestão era a abrangência, ao afirmava costumeiramente que o público do ministério não era apenas os criadores e produtores culturais, mas toda a sociedade brasileira. O diálogo com a sociedade e a ideia da ampliação do conceito de cultura foi, para Rubem (2008) outro desafio, pois isso exigiu enfrentar o autoritarismo e o elitismo. Formular e implementar políticas culturais em circunstâncias democráticas foi o ponto forte de Gil, que "teceu uma poética relação entre políticas culturais e cultura" (Rubim, 2008: 194).

Com Gilberto Gil e a sua visão antropológica, a própria definição de cultura mudou para efeitos das ações e formulações das políticas culturais, pois foi convertida em parte do desenvolvimento social (Miranda, 2010). Nesta mesma linha, Lia Calabre (2007), historiadora e chefe do setor de Estudos de Política Cultural da Fundação Casa 
de Rui Barbosa (FCRB), o campo de políticas públicas de cultura no Brasil é um campo em construção, "em termos gerais podemos dizer que os primeiros quatro anos de gestão do Ministro Gil foram de construção real de um Ministério da Cultura [que havia passado, desde sua criação, em 1985] por uma série de crises e processos de descontinuidade" (Calabre, 2007, p. 98). A conjuntura herdada por Gilberto Gil foi de uma política de Estado mínimo depois de uma gestão de oito anos do Ministro Weffort, do governo do Presidente Fernando Henrique Cardoso, com diversas dificuldades operacionais. Mas, logo no início do ministério de Gil foram percebidas algumas mudanças na utilização da Lei Rouanet e demais editais, seguido da criação e vigência do Plano Nacional de Cultura, além da participação social nas definições das políticas (Reis, 2020).

O ministro Gilberto Gil trouxe para a cultura uma nova forma de administrar através de audiências públicas, discussões com a sociedade, também no campo da produção cultural e da economia da cultura. Embora o debate sobre valorização da cultura popular tenha iniciado no século XIX na Europa, esse processo se construiu em cima de um romantismo em torno do tema. No Brasil, as culturas populares ainda estavam atreladas às relações estabelecidas pelo Estado. Não cabe ao Estado definir, delimitar ou responder o que é "Cultura Popular”. Diante disso, Gil trouxe contribuições importantes para essas e outras reflexões, que vão além da cultura erudita, da cultura popular, da cultura de mercado, entre outras formas de manifestações, abrindo espaços para o debate político entre a sociedade: artistas, produtores culturais, investidores, gestores e representantes da sociedade através das conferências (id.). Com Gilberto Gil, o Brasil ganhou um ministério com cultura, liderando uma série de consultas públicas que abriram espaços de diálogo com a sociedade civil e com participação de diversos segmentos da área artística.

\section{A ampliação do conceito de cultura}

Um conceito abrangente de cultura em sua dimensão antropológica e simbólica. Essa era a métrica de Gilberto Gil à frente do MinC. Para ele, era fundamental a articulação entre cultura e cidadania. Gil defendeu uma democratização das políticas culturais, englobando culturas populares, afro-brasileiras, indígenas, mulheres, LGBT, das periferias, das novas tecnologias, entre muitas outras (Reis, 2020). A ideia de implementar um conceito abrangente de cultura e lançar um olhar para outros modos de 
fazer cultura - a cultura popular, a cultura de massa, a cultura da periferia, a cultura dos candomblés - implicou em uma mudança de perspectiva social sobre as políticas públicas.

Rubim (2008) enfatiza que a atuação do Ministério da Cultura foi, no período Gil, para além da chamada classe artística. Um exemplo foi o apoio às culturas indígenas, às culturas populares, à cultura digital e até mesmo à cultura midiática audiovisual, mas também o projeto DOC-TV, que associou o ministério à rede pública de televisão para produzir documentários em todo o país; o edital para jogos eletrônicos; os apoios às paradas gay; os seminários nacionais de culturas populares; as câmaras setoriais; as conferências, inclusive culminando na Conferência Nacional de Cultura:

\footnotetext{
A abertura conceitual e de atuação significa não só o abandono de uma visão elitista e discriminadora de cultura, mas representa um contraponto ao autoritarismo e a busca da democratização das políticas culturais. A intensa opção por construir políticas públicas em debate com a sociedade emerge como outra marca da gestão Gil (Rubim, 2008: 196).
}

Botelho (2007: 110) faz uma reflexão em torno do conceito "ampliado de cultura". A autora considera que vale a continuidade e a incorporação da dimensão antropológica da cultura, tendo em vista "a formação global do indivíduo, a valorização de seus modos de viver, pensar e fruir, de suas manifestações simbólicas e materiais". Além disso, essa abertura fomentou o enriquecendo cultural, expandindo a capacidade das pessoas de agir sobre o mundo, a qualidade de vida e a cidadania. O Ministério da Cultura deu início a um intenso processo de discussão e reorganização do papel do Estado na cultura, não somente na questão conceitual, mas também na recuperação do orçamento e a distribuição dos recursos buscando um equilíbrio regional. Partindo de um conceito ampliado de cultura, que inclui saberes e fazeres, foi possível pensar a cultura não somente em seu sentido artístico. Logo, a elaboração de uma política cultural pode ser pensada como bem da coletividade, passando pelas mais diversas áreas governamentais, como "saúde, educação, meio ambiente, planejamento urbano, entre outras" (Calabre, 2007: 96).

Ao mesmo tempo em que se trabalhou na ampliação da visão da cultura, as políticas do ministério de Gil direcionaram suas ações ao conhecimento, trazendo a reflexão para o cotidiano das pessoas. Esse foi o foco da nova política cultural. Em 2020, a deputada Benedita da Silva, ao lembrar o legado que Gil nos deixou, lembrou que o exministro humanizou o desenvolvimento socioeconômico do país e também investiu em proteção da identidade e da diversidade cultural por meio da participação em uma vida 
cultural mais democrática. Gil não somente ampliou os conceitos e garantias do direito à identidade e à diversidade cultural, mas também respeitou o cumprimento da constituição que instituiu proteção especial para as culturas populares, indígenas e afro-brasileiras (Simões, 2020).

Em contraposição ao modelo econômico neoliberal, Gil realizou um novo projeto político através da ampliação do conceito de cultura abrindo as fronteiras do ministério para outras expressões e formas fazer cultura como, por exemplo, as culturas populares, afro-brasileiras, indígenas, ciganas, de gênero, de orientações sexuais, das periferias, audiovisuais, digitais, entre outras (Reis, 2020). "Quero que esta aqui seja a casa de todos os que pensam e fazem o Brasil. Que seja, realmente, a casa da cultura brasileira" (Gil, 2003). Mesmo assim,

o complexo e tumultuado processo vivido pelo Ministério, por certo, possibilita avaliações diferenciadas e polêmicas acerca das possíveis continuidades e descontinuidades, mas ele impõe outra constatação: o patamar político e cultural alcançado pelo Ministério nas gestões de Gilberto Gil e Juca Ferreira foi visivelmente deprimido. A forte presença na cena pública se quedou comprometida (Rubim, 2015 apud Reis, 2020: 28).

A política de Gil não se deteve apenas nas questões de democratização simbólica, cidadã e econômica, mas também atuou na ampliação do acesso à Lei de Incentivo Fiscal, tanto por parte dos proponentes quanto por parte dos patrocinadores. Em 2008, foi criado o Diálogos Culturais, que eram encontros com patrocinadores e empresas que tinham potencial para patrocinar projetos via incentivo fiscal, um dos mecanismos da Lei Rouanet.

Entendemos que políticas públicas devem ser aquelas que transcendam governos e que possam se tornar permanentes. Existe uma discussão atual a respeito do conceito de democracia, e defende que as decisões sobre as políticas culturais devam ser partilhadas entre esfera pública não estatal, por meio de diálogos "entre Estado, conselhos, fóruns deliberativos, organizações sociais e a população" (Canedo, 2009: 80) . E por mais que entrem governos democráticos representativos, os direitos dos cidadãos estão na possibilidade de participar através das eleições, onde elegem representantes para a elaboração e o cumprimento das leis. Entretanto, até que ponto a população tem participado de forma legítima das decisões do governo?

Uma das principais críticas é que esta representação política se manifesta por uma “classe de políticos profissionais, responsáveis por gerir a coisa pública, enquanto o 
restante da população se mantém afastado das questões políticas" (Canedo, 2009: 82). Mais que isso,

\begin{abstract}
a partir de 2003, o ministério encarou o direito à cultura como um dos princípios basilares da cidadania. Entre as mudanças propagadas e instaladas pela gestão Gilberto Gil, vale destacar: 1) o alargamento do conceito de cultura, que passa a ser compreendida a partir de uma concepção mais próxima da visão antropológica; sendo assim, 2) o público-alvo das ações governamentais é deslocado do artista para a população em geral; e 3) o Estado, então, retoma seu lugar como agente principal na execução das políticas culturais; ressaltando a importância 4) da participação da sociedade na elaboração dessas políticas; e 5) da divisão de responsabilidades entre os diferentes níveis de governo, as organizações sociais e a sociedade para a gestão das ações (Canedo, 2009, p. 84).
\end{abstract}

Políticas culturais devem ter dispositivos democráticos e republicanos, respeitando a liberdade de criação e assegurando a participação ampla das comunidades culturais, além de incentivar o desenvolvimento e a diversidade de públicos e mercados culturais (Rubim, 2016). Ainda que entendendo que a política cultural no Brasil não possua os dispositivos adequados para incorporar novos ativistas culturais, Rubim (2016: 275) concorda que "com a ampliação do conceito de cultura e com a promoção da diversidade cultural" novos agentes e comunidades passaram a demandar e ser atendidos pelo Estado.

Os programas desenvolvidos na gestão de Gil, como o Cultura Viva e o Mais Cultura, trouxeram forte apelo da importância da cultura para o desenvolvimento no país. Em suas palavras, na abertura da $1^{\text {a }}$ Conferência Nacional da Cultura, "cultura na cesta básica dos brasileiros". Ele afirmava que a cultura deve ser definida a partir de um novo conceito: "Cultura não mais como ornamento, como jarro de flores nas mesas das elites, mas como algo básico, na cesta básica de todos os brasileiros” (MinC, 2005, apud Reis, 2020, p. 112). A esse respeito, em uma declaração para o Jornal Folha de São Paulo Gil expressou: "temos fome e sede de cultura neste país. Chegou a hora de valorizarmos o alimento espiritual". Bem como o patrimônio histórico tem importância vital na "nossa cesta básica cultural", que pode até mesmo representar o nosso "feijão com o arroz do espírito". Na visão de Gil, a memória cultural brasileira deve passar a ser "ingrediente fundamental no nosso fogão da alma". Segundo ele, "ninguém pensa o presente ou sonha o futuro sem se alimentar da história, do passado" (Folha de São Paulo, 2003).

Para Gil, algumas questões eram fundamentais, e para isso o MinC deveria atuar em algumas pontas, como a ampliação do conceito de cultura, a valorização dos conceitos 
de políticas públicas de cultura, o planejamento e as ações sistêmicas, mudanças nas metas e nas diretrizes, o desenvolvimento de estratégias para a cultura dentro do ministério e estabelecimento de um diálogo com a comunidade artística, produtores e estudiosos de cultura. O ministro defendia uma política de universalização e qualificação, políticas compensatórias, política de distribuição primária da renda e, por fim, política de regulação e incentivo ao mercado (Gil, apud Almeida et al., 2013).

Gilberto Gil trouxe um novo olhar ao modo de fazer políticas culturais no Brasil. Através da ampliação do conceito de cultura houve uma abertura em diversas pontas, nas ideias, na participação social e na própria reflexão sobre o que é política pública de cultura. Para ele, falar de cultura é falar sobre a essência da vida humana, de algo vital tanto como o ar quanto a natureza. Por isso a necessidade de conectar a cultura a todas as dimensões da existência, que faz o mundo funcionar seja na economia seja na política. Com relação às críticas por ser artista e ocupar um cargo de ministro, ele dizia que nada mais natural que a incursão de um ministro-artista para a cultura, afinal este território já foi tão exclusivo de economistas (Gil, apud Almeida et al., 2013; Reis, 2020).

Esta ampliação do conceito de cultura do Ministério da Cultura não se deu apenas nas ideias, mas também na abertura do diálogo entre diversos atores da sociedade civil. Para Gil, o MinC precisava fazer esse "aggiornamento da questão conceitual da cultura" (Gil, apud Almeida et al., 2013: 103) e conforme defendeu em seu discurso de posse (id.), era preciso fazer uma política que atingisse todas as camadas da população: "quero o Ministério presente em todos os cantos e recantos de nosso País".

\section{Considerações finais}

Gilberto Gil deixou um legado ao MinC: a inclusão de novos agentes, a abertura para debates, o reconhecimento e respeito pela diversidade. O ano de 2003 marcou uma nova forma de fazer política pública na área da cultura. A retomada da construção do Plano Nacional de Cultura, principalmente na forma como ocorreu sua construção através da participação ampla da sociedade civil equacionando a diversidade de relações no processo de constituição da agenda cultural e de outras políticas.

O novo modo de fazer política se traduziu, justamente, nas diversas frentes em que a gestão do Ministro Gilberto Gil atuou. Quando ele falava sobre a necessidade da ampliação do conceito de cultura, essa abertura não era somente uma questão conceitual. 
A ideia ia além de um conceito, ela se referia ao modo de fazer política cultural. Estava intrínseca a intenção de uma transformação na prática cultural efetiva desenvolvida pelo Ministério. Gilberto Gil defendia uma política pública de cultura que ultrapassasse o tempo, que permanecesse além dos governos. Não foi por acaso que ele abriu espaços para o diálogo e para a construção de políticas, abrindo para diversos atores sociais, e não somente formulações de políticas dentro do aparato do governo. Uma política pública de cultura com maior participação social, de modo que elas pudessem contribuir com suas ideias, falar de suas necessidades. Deste modo, ele transformou ideias em programas, e programas em Leis, possibilitando maior garantia para as ações e para as políticas que foram construídas naquele período (todas ainda permanecem, algumas estão ativas outras temporariamente paradas, mas nenhuma foi extinta até o momento).

A ampliação do conceito de cultura certamente influenciou nas decisões para a implementação das novas políticas trazidas por Gilberto Gil. O ex-ministro, quando afirmava que o principal problema do Brasil eram as desigualdades, estava definindo o problema através de observações da dinâmica social, adotando estratégias e estabelecendo metas e objetivos para realizar uma mudança na política cultural. Gil tinha a compreensão de que investir em uma política pública de cultura tem essa conotação de público - trazer todos os públicos para fazer política, os artistas, a sociedade civil, a diversidade de experiências, de práticas, de sentidos, histórias e tradições. Era a melhor forma para se pensar além de uma "Cultura" com C maiúsculo - a das "normas cultas", como ele costumeiramente fazia referência. O exercício de antropologia aplicada era, para Gil, uma saída da prisão, - era um "olhar para nós” para "expandir a consciência de quem somos".

\section{REFERÊNCIAS}

ALMEIDA, Armando et al. (org.). Gilberto Gil \& Juca Ferreira. Cultura pela Palavra: Coletânea de artigos, entrevistas e discursos dos ministros da Cultura (2003-2010). Rio de Janeiro, Versal, 2013.

BOLAÑO, César et al. (org). Economia da arte e da cultura. São Paulo: Itaú Cultural; São Leopoldo: Cepos/Unisinos; Porto Alegre: PPGCOM/UFRGS; São Cristóvão: Obscom/UFS, 2010. 
BOTELHO, Isaura. A política cultural \& o plano das ideias. IN: RUBIM, Antônio Albino e BARBALHO, Alexandre (org.). Políticas culturais no Brasil. Salvador, EDUFBA, 2007.

BRASIL. DECRETO Nº 6.177, DE $1^{\circ}$ DE AGOSTO DE 2007. Diário Oficial da União Brasília, DF, Seção 1, 02 ago. 2007.

CALABRE, Lia. (Org). Políticas culturais: reflexões e ações. São Paulo/Rio de Janeiro: Itaú Cultural/Fundação Casa Rui Barbosa, 2009.

Notas sobre os rumos das políticas culturais no Brasil nos anos 2011-2014. In: RUBIM, Antonio; BARBALHO, Alexandre; CALABRE, Lia. (Org). Políticas culturais no governo Dilma. Salvador: EDUFBA, 2015. 281 p.

CANEDO, Daniele. A participação social na elaboração de políticas públicas de cultura na Bahia. In: CALABRE, Lia. (Org). Políticas culturais: reflexões sobre gestão, processos participativos e desenvolvimento. São Paulo/Rio de Janeiro: Itaú Cultural/Fundação Casa Rui Barbosa, 2009.

FOLHA DE SÃO PAULO (2003). 'Prefeito que não foi', Gilberto Gil era empossado vereador de Salvador há 30 anos. UOL. Disponível em: https://www1.folha.uol.com.br/poder/2019/03/prefeito-que-nao-foi-gilberto-gil-eraempossado-vereador-de-salvador-ha-30-anos.shtml. Acesso em: 28. Set. 2020.

GIL, Gilberto (2003). Discursos do Ministro da Cultura Gilberto Gil. Brasília: Ministério da Cultura. Disponível em: <www.cultura.gov.br>. Acesso em: 07 jul. 2020.

REIS, Adriana Donato dos. Ministério com Cultura: gestão Gilberto Gil (2003-2008). Tese de Doutorado. Programa de Pós-Graduação em Políticas Públicas, Instituto de Filosofia e Ciências Humanas. Porto Alegre: Universidade Federal do Rio Grande do Sul, 2020. 
RUBIM, Antonio Albino Canelas (org). Políticas culturais no Brasil, Salvador: edufba, 2007.

Políticas culturais do governo Lula / Gil: desafios e enfrentamentos. Intercom Revista Brasileira de Ciências da Comunicação, São Paulo, v.31, n.1, p. 183-203, jan/jun. 2008.

Entrevista com Gilberto Gil. Ministro da Cultura no período de 2003 a 2008. Entrevista realizada em 30 de março de 2009, Salvador, Bahia. Disponível em $<$ https://repositorio.ufba.br/ri/bitstream/ri/1363/1/3110.pdf $>$. Acesso em: 04 out. 2020.

. Teses sobre financiamento e fomento à cultura no Brasil. IN: VALIATI, Leandro; MOLlER, Gustavo (org.). Economia Criativa e Políticas Públicas. Porto Alegre: Editora UFRGS/CEGOV, 2016.

SIMÕES, Nataly. Alma Preta - de Gilberto Gil a Regina Duarte: para onde vai a Cultura no Brasil? 2020. Disponível em: <https://almapreta.com/editorias/realidade/de-gilbertogil-a-regina-duarte-para-onde-vai-a-cultura-no-brasil>. Acesso em: 07 jun. 2020.

UOL. Orçamento em Cultura aumenta $142 \%$ desde 2003. Disponível em: $<$ https://congressoemfoco.uol.com.br/especial/noticias/orcamento-em-cultura-aumenta142-desde-2003/>. Acesso em: 24 out. 2019.

Recebido: 13/01/2021

Aprovado: 12/02/2021 